\title{
Time trends of short-term mortality for octogenarians undergoing a colorectal resection in North Europe
}

Citation for published version (APA):

Claassen, Y. H. M., Bastiaannet, E., van Eycken, E., Van Damme, N., Martling, A., Johansson, R., Iversen, L. H., Ingeholm, P., Lemmens, V. E. P. P., Liefers, G. J., Holman, F. A., Dekker, J. W. T., Portielje, J. E. A., Rutten, H. J., \& van de Velde, C. J. H. (2019). Time trends of short-term mortality for octogenarians undergoing a colorectal resection in North Europe. European Journal of Surgical Oncology, 45(8), 1396-1402. https://doi.org/10.1016/j.ejso.2019.03.041

Document status and date:

Published: 01/08/2019

DOI:

10.1016/j.ejso.2019.03.041

Document Version:

Publisher's PDF, also known as Version of record

Document license:

Taverne

Please check the document version of this publication:

- A submitted manuscript is the version of the article upon submission and before peer-review. There can be important differences between the submitted version and the official published version of record.

People interested in the research are advised to contact the author for the final version of the publication, or visit the DOI to the publisher's website.

- The final author version and the galley proof are versions of the publication after peer review.

- The final published version features the final layout of the paper including the volume, issue and page numbers.

Link to publication

\footnotetext{
General rights rights.

- You may freely distribute the URL identifying the publication in the public portal. please follow below link for the End User Agreement:

www.umlib.nl/taverne-license

Take down policy

If you believe that this document breaches copyright please contact us at:

repository@maastrichtuniversity.nl

providing details and we will investigate your claim.
}

Copyright and moral rights for the publications made accessible in the public portal are retained by the authors and/or other copyright owners and it is a condition of accessing publications that users recognise and abide by the legal requirements associated with these

- Users may download and print one copy of any publication from the public portal for the purpose of private study or research.

- You may not further distribute the material or use it for any profit-making activity or commercial gain

If the publication is distributed under the terms of Article $25 \mathrm{fa}$ of the Dutch Copyright Act, indicated by the "Taverne" license above, 


\section{Time trends of short-term mortality for octogenarians undergoing a colorectal resection in North Europe}

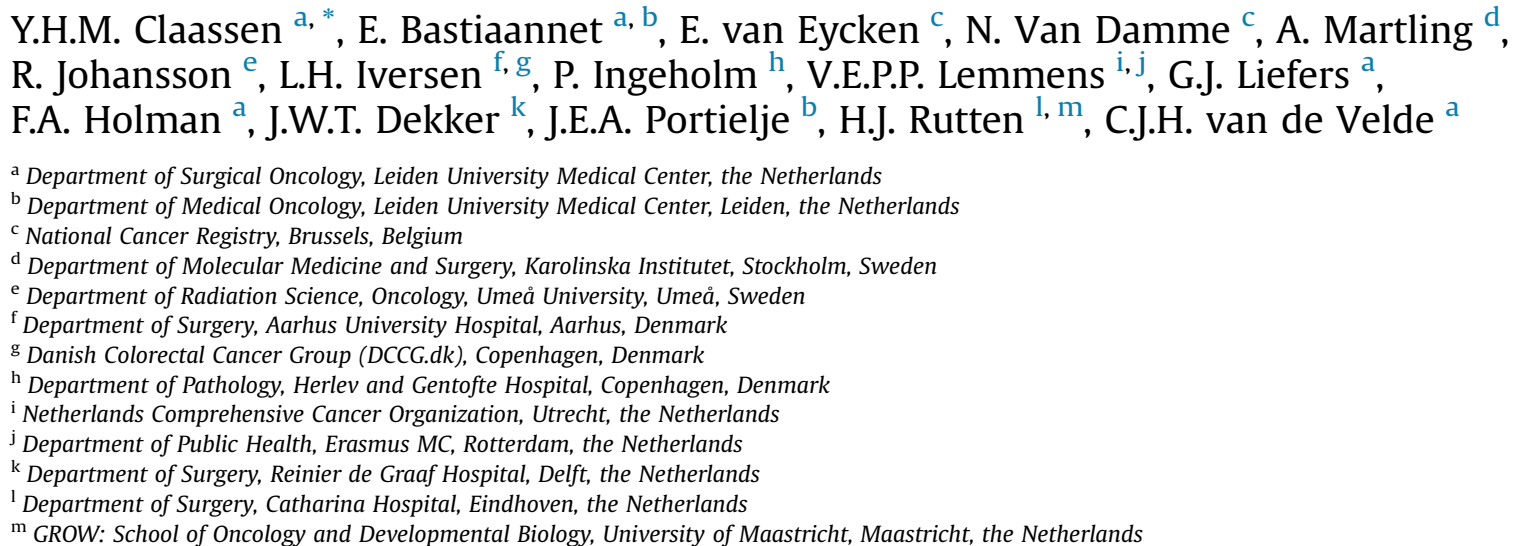

\section{A R T I C L E I N F O}

\section{Article history:}

Received 8 January 2019

Received in revised form

10 March 2019

Accepted 28 March 2019

Available online 9 April 2019

\section{Keywords}

Colorectal cancer

Short-term mortality

Elderly

Octogenarians

\begin{abstract}
A B S T R A C T
Background: Decreased cancer specific survival in older colorectal patients is mainly due to mortality in the first year, emphasizing the importance of the first postoperative year. This study aims to gain an overview and time trends of short-term mortality in octogenarians ( $\geq 80$ years) with colorectal cancer across four North European countries.

Methods: Patients of 80 years or older, operated for colorectal cancer (stage I-III) between 2005 and 2014, were included. Population-based cohorts from Belgium, Denmark, the Netherlands, and Sweden were collected. Separately for colon- and rectal cancer, 30-day, 90-day, one-year, and excess one-year mortality were calculated. Also, short-term mortality over three time periods (2005-2008, 2009-2011, 2012 -2014) was analyzed.

Results: In total, 35,158 colon cancer patients and 10,144 rectal cancer patients were included. For colon cancer, 90-day mortality rate was highest in Denmark (15\%) and lowest in Sweden (8\%). For rectal cancer, 90-day mortality rate was highest in Belgium (11\%) and lowest in Sweden (7\%). One-year excess mortality rate of colon cancer patients decreased from 2005 to 2008 to 2012-2014 for all countries (Belgium: $17 \%-11 \%$, Denmark: $21 \%-15 \%$, the Netherlands: $18 \%-10 \%$, and Sweden: $10 \%-8 \%$ ). For rectal cancer, from 2005 to 2008 to $2012-2014$ one-year excess mortality rate decreased in the Netherlands from $16 \%$ to $7 \%$ and Sweden: $8 \%-2 \%$ ).

Conclusions: Short-term mortality rates were high in octogenarians operated for colorectal cancer. Shortterm mortality rates differ across four North European countries, but decreased over time for both colon and rectal cancer patients in all countries.
\end{abstract}

() 2019 Published by Elsevier Ltd.
* Corresponding author. Department of Surgery, K6-43 Leiden University Medical Center, PO Box 9600, 2300 RC, Leiden, the Netherlands.

E-mail addresses: y.h.m.claassen@lumc.nl (Y.H.M. Claassen), C.J.H.van_de_ Velde@lumc.nl (C.J.H. van de Velde).

\section{Introduction}

Colorectal cancer is one of the most common types of cancer, accounting for an estimated number of 471,000 new cases and 228,000 deaths in Europe in 2012 [1]. Colorectal cancer is 
predominantly a disease of the elderly, as approximately one fifth of all colorectal patients is older than 80 years [2]. This number is expected to increase as the population ages.

Several population based studies showed an impaired cancer related survival for older patients with colorectal cancer compared to their younger counterparts with colorectal cancer [3-5]. The EUROCARE-5 study showed a European average 5-year relative survival for colon and rectal cancer patients of 75 years or older of $49 \%$ and $44 \%$, respectively, whereas 5 -year relative survival for all ages were $57 \%$ and $56 \%$ [5]. Several aspects might explain these findings. Firstly, older colorectal cancer patients are more often diagnosed with an advanced stage of disease. Also they suffer more often from comorbidities that may contribute to a higher rate of postoperative complications, but also intervene with adjuvant treatments. Furthermore, they have a greater risk of dying due to complications or other diseases that are accelerated during cancer treatment [6-8].

A crucial component of the impaired cancer-specific survival in older colorectal cancer patients is the increased short-term mortality [9]. Short-term mortality is defined as mortality in the first postoperative year. Literature has shown that one-year mortality in colorectal cancer is highly influenced by age [10]. In a singleinstitution in Cleveland (Ohio, United States of America) 2485 patients with stages I-III colorectal adenocarcinoma who underwent an electively radical resection were included. In this study, octogenarians (patients of 80 years or older) had a one-year overall mortality of $37 \%$ after a colorectal cancer resection, whereas patients of 65 years or younger had a one-year mortality of $7 \%$ [10]. This study was limited by selection bias due to including patients for surgery of a single tertiary referral center and a limited number of patients.

Large population-based studies regarding short-term mortality in older colorectal cancer patients are scarce. Therefore, population-based data of colorectal cancer patients, aged 80 years or older, of Belgium, Denmark, the Netherlands, and Sweden were collected. The current study aimed to report short-term mortality rates (30-day, 90-day, one-year, and excess one-year mortality rates) of octogenarians with colorectal cancer in these four European countries. We focused on time trends of short-term mortality as a decrease of 30- and 90-day mortality was observed for both colon and rectal cancer over time in the Netherlands since 2005 [11].

\section{Material and methods}

\section{Data and study population}

Patients of 80 years or older, operated (irrespective of priority) for their primary colorectal cancer between January 1, 2005, and 31, December 2014, were included. Data were collected from the Belgian Cancer Registry, the Danish Colorectal Cancer Group database, the Netherlands Cancer Registry, and the Swedish Colorectal Cancer Registry. As in Sweden the colon cancer register was added from 2007 and forward, only Swedish data of colon cancer patients between 2007 and 2014 were available [12]. Colorectal cancer was defined as C18 (colon), C19 and C20 (rectal), according to the international Classification of Diseases and Related Health Problems [13]. Stage I-III of disease were included. The TNM Classification of Malignant Tumors (5th, 6th, or 7th edition) was used for defining tumor stage [14]. Tumor stage was based on pathological stage; in case this was missing clinical stage was used. Vital status and date of death were assessed either directly from the patient's medical record or through linkage of cancer registry data to population files on vital status. Follow up time was defined as the time from date of surgery until death or until end of follow up (censored). Surgery was defined as surgical resection of the tumor. Local excisions were included while construction of a stoma without tumor resection and endoscopic techniques were excluded. Patients were excluded from the analyses of 30-day, 90-day, and 1-year (excess) mortality in case the follow up data was missing. Of the follow-up data of the colon and the rectal cancer patients $0.1 \%$ and $0.2 \%$, respectively, was missing.

\section{Statistics}

Short-term mortality analyses were performed separately for colon cancer and rectal cancer patients. Short-term mortality analyses consisted of the calculation of overall 30-day, overall 90-day, overall one-year mortality, and excess one-year mortality for each country. The excess 1-year mortality was calculated as: the observed mortality in one year minus the expected mortality divided by the number of patients in that specific selection. Expected mortality was calculated by matching the cohort to a general population file by age, sex and year. National life tables of the respective countries were used to estimate the expected survival. This is the most preferable method to obtain a prognosis of elderly as the risk of dying due to other causes is taken into account. Furthermore, short-term mortality over three time periods (2005-2008, 2009-2011, 2012-2014) was analyzed. Relative risk reduction of excess one-year mortality was calculated and defined as relative decrease from 2012 to 2014 compared to 2005-2008. The short-term mortality analyses were also performed for age subgroups (80-84 year, 85-89 year, and $90+$ year). All analyses were compared between the participating countries.

STATA/SE version 12.0 was used for the statistical analyses.

\section{Results}

\section{Patient and tumor characteristics}

Between January 1, 2005 and 31, December 2014, a total of 45,302 colorectal patients of 80 years or older were identified. Among them, 35,158 patients were diagnosed with colon cancer and 10,144 patients with rectal cancer. Patient and tumor characteristics of the colon cancer and rectal cancer are presented in Table 1 . In all countries the majority of colon cancer patients was diagnosed with stage II disease. For rectal cancer, the majority of patients had stage III disease. Of the colon cancer patients, $1.8 \%$ of the patients (average of the countries) had an unknown stage compared to $3.6 \%$ of the rectal cancer patients (average of the countries).

\section{Overall 30-day, 90-day, and 1-year (excess) mortality}

Table 2 shows an overview of the short-term mortality rates of octogenarians. The lowest 90-day mortality rate of colon cancer patients was found in Sweden (7.9\%). Ninety-day mortality rate was $12.6 \%$ in Belgium, $13.6 \%$ in the Netherlands, and $14.9 \%$ in Denmark. Excess 1-year mortality rate for colon cancer patients varied from $8.6 \%$ in Sweden to $17.7 \%$ in Denmark. Also for rectal cancer patients, the lowest 90 -day mortality rate was seen in Sweden $(7.2 \%$ versus $10.9 \%$ in the Netherlands, $11.2 \%$ in Denmark, and $11.3 \%$ in Belgium). The excess 1-year mortality rate was the lowest in Sweden (5.3\%) and the highest in Belgium (14.0\%).

For colon cancer, in all countries ninety-day mortality rate increased with increasing age category (Belgium: $80-84$ year: $9.9 \%$, $85-89$ year: $15.0 \%$, 90 + year: $21.5 \%$; Denmark: $80-84$ year: $12.3 \%$, 85-89 year: $15.7 \%$, 90 + year: $29.0 \%$, The Netherlands: $80-84$ year: 10.9\%, 85-89 year: $16.7 \%$, 90 + year: $24.0 \%$, Sweden: $80-84$ year: $5.8 \%$, 85-89 year: $10.1 \%$, 90 + year: $13.3 \%)$. For rectal cancer, $90-$ day 
Table 1

Patient and tumor characteristics of stage I-III colon and rectal cancer patients of 80 years and older who underwent surgery and were diagnosed during 2005 and 2014.

\begin{tabular}{|c|c|c|c|c|}
\hline \multicolumn{5}{|l|}{ COLON CANCER } \\
\hline & Belgium & Denmark & the Netherlands & Sweden \\
\hline Total & $10,513(100)$ & $4192(100)$ & $14,218(100)$ & $6235(100)$ \\
\hline \multicolumn{5}{|l|}{ Sex } \\
\hline Male & $4521(43.0)$ & $1686(40.2)$ & $6126(43.1)$ & $2610(41.9)$ \\
\hline Female & $5992(57.0)$ & $2506(59.8)$ & $8092(56.9)$ & $3625(58.1)$ \\
\hline \multicolumn{5}{|l|}{ Grade } \\
\hline I & $1754(16.7)$ & $*$ & $928(6.5)$ & $427(6.8)$ \\
\hline II & $5773(54.9)$ & $*$ & $9394(66.1)$ & $2912(46.7)$ \\
\hline III & $1898(18.1)$ & $*$ & $2398(16.9)$ & $1076(17.3)$ \\
\hline Unknown & $1088(10.8)$ & $*$ & $1498(10.5)$ & $1820(29.2)$ \\
\hline \multicolumn{5}{|l|}{ Stage } \\
\hline I & $1748(16.6)$ & $559(13.3)$ & 3066 (21.6) & $972(15.6)$ \\
\hline II & $5056(48.1)$ & $2240(53.4)$ & 6641 (46.7) & $3010(48.3)$ \\
\hline III & 3709 (35.3) & $1393(33.2)$ & $4511(31.7)$ & $2253(36.1)$ \\
\hline \multicolumn{5}{|c|}{ Year of diagnosis } \\
\hline $2005-2008$ & 3537 (33.6) & $1566(37.4)$ & $5299(37.3)$ & $1496(24.0)^{\wedge}$ \\
\hline $2009-2011$ & 3147 (29.9) & $1219(29.1)$ & $4544(32.0)$ & $2321(37.2)$ \\
\hline $2012-2014$ & $3829(36.4)$ & $1407(33.6)$ & $4375(30.8)$ & $2418(38.8)$ \\
\hline \multicolumn{5}{|c|}{ RECTAL CANCER } \\
\hline & Belgium & Denmark & the Netherlands & Sweden \\
\hline Total & $2890(100)$ & $1103(100)$ & $3952(100)$ & $2199(100)$ \\
\hline \multicolumn{5}{|l|}{ Sex } \\
\hline Male & $1498(51.8)$ & $560(50.8)$ & $2020(51.1)$ & $1183(53.8)$ \\
\hline Female & $1392(48.2)$ & $543(49.2)$ & 1932 (48.9) & $1016(46.2)$ \\
\hline \multicolumn{5}{|l|}{ Grade } \\
\hline I & $471(16.3)$ & $*$ & $213(5.4)$ & $183(8.3)$ \\
\hline II & $1757(60.8)$ & $*$ & $2083(52.7)$ & $1138(51.8)$ \\
\hline III & $351(12.1)$ & $*$ & $296(7.5)$ & $168(7.6)$ \\
\hline Unknown/NA & $311(10.8)$ & $*$ & $1360(34.3)$ & $710(32.3)$ \\
\hline \multicolumn{5}{|l|}{ Stage } \\
\hline I & $817(28.3)$ & $281(25.5)$ & $1212(30.7)$ & $682(31.0)$ \\
\hline II & $1004(34.7)$ & $429(38.9)$ & $1257(31.8)$ & 738 (33.6) \\
\hline III & $1069(37.0)$ & $393(35.6)$ & $1483(37.5)$ & $779(35.4)$ \\
\hline \multicolumn{5}{|c|}{ Year of diagnosis } \\
\hline $2005-2008$ & 1143 (39.6) & $447(40.5)$ & $1598(40.4)$ & $904(41.1)$ \\
\hline $2009-2011$ & 915 (31.7) & $348(31.6)$ & $1189(30.1)$ & $686(31.2)$ \\
\hline $2012-2014$ & $832(28.8)$ & 308 (27.9) & $1165(29.5)$ & $609(27.7)$ \\
\hline
\end{tabular}

$*$ not registered in Danish dataset.

= no data available of 2005 and 2006.

mortality rate rose as well with increasing age category (Belgium: 80-84 year: $9.0 \%$, 85-89 year: $14.1 \%$, 90 + year: $22.3 \%$; $15.2 \%$, Denmark: $80-84$ year: $9.7 \%, 85-89$ year: $15.2 \%, 90+$ year: $10.9 \%$, The Netherlands: $80-84$ year: $10.1 \%, 85-89$ year: $11.9 \%, 90+$ year: 17.0\%, Sweden: $80-84$ year: $6.6 \%, 85-89$ year: $7.4 \%, 90+$ year: $12.7 \%)$.

Overall 30-day, 90-day, and 1-year (excess) mortality over time

A decrease of 30-day, 90-day, one-year mortality, and excess 1-year mortality rate is observed over time in colon cancer patients in Belgium, Denmark, the Netherlands, and Sweden (Fig. 1a). From 2005 to 2008 to 2011-2014 relative risk reduction of the excess 1-year mortality rate in colon cancer patients was more than $40 \%$ the Netherlands ( $42.7 \%$, absolute difference: $-7.6 \%$ ), followed by Belgium (32.5\%, absolute difference: $-5.5 \%)$, Denmark (29.4\%, absolute difference: $-6.3 \%)$, and Sweden $(23.0 \%$, absolute difference: $-2.3 \%)$. For rectal cancer, from 2005 to 2008 to
2011-2014 the highest relative reduction of excess 1-year mortality rate occurred in Sweden (70.0\%, absolute difference: $-5.8 \%$ ), followed by the Netherlands (58.1\%, absolute difference: $-9.0 \%$ ), Belgium (6.7\%, absolute difference: $-0.8 \%$ ), and Denmark (3.8\%, absolute difference: $-0.5 \%)$.

\section{Discussion}

In this analysis including more than 45,000 patients aged 80 years or more undergoing a colorectal resection, the variety and time trends of short-term mortality were evaluated across four North European countries. Short-term mortality rates were high and substantial differences were seen between the countries. For both colon and rectal cancer patients short-term mortality rates decreased over time in all countries.

In literature it is shown that decreased survival in older colorectal cancer patients is mainly due to mortality in the first postoperative year [9,15]. This study showed high rates of short-term 
Table 2

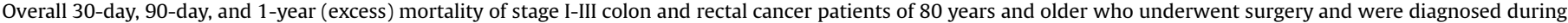
2005 and 2014.

\begin{tabular}{|c|c|c|c|c|}
\hline \multicolumn{5}{|l|}{ COLON CANCER } \\
\hline & Belgium & Denmark & the Netherlands & Sweden \\
\hline 30-day mortality (\%) & 7.8 & 11.4 & 10.3 & 5.5 \\
\hline Stage I & 5.8 & 6.3 & 7.4 & 2.8 \\
\hline Stage II & 7.5 & 11.3 & 10.2 & 5.3 \\
\hline Stage III & 9.0 & 13.4 & 12.5 & 7.0 \\
\hline 90-day mortality (\%) & 12.6 & 14.9 & 13.6 & 7.9 \\
\hline Stage I & 9.6 & 10.0 & 9.8 & 4.1 \\
\hline Stage II & 12.1 & 14.3 & 13.3 & 7.2 \\
\hline Stage III & 14.7 & 17.7 & 16.7 & 10.6 \\
\hline 1-year mortality (\%) & 23.3 & 23.6 & 22.4 & 17.1 \\
\hline Stage I & 14.9 & 15.7 & 14.9 & 8.4 \\
\hline Stage II & 20.3 & 20.0 & 19.8 & 13.8 \\
\hline Stage III & 31.4 & 32.7 & 31.2 & 25.4 \\
\hline Excess 1-year mortality (\%) & 15.0 & 17.7 & 14.2 & 8.6 \\
\hline Stage I & 6.5 & 10.2 & 6.5 & 0.1 \\
\hline Stage II & 11.6 & 14.1 & 11.4 & 5.0 \\
\hline Stage III & 23.6 & 26.6 & 23.5 & 17.2 \\
\hline \multicolumn{5}{|l|}{ RECTAL CANCER } \\
\hline & Belgium & Denmark & the Netherlands & Sweden \\
\hline 30-day mortality (\%) & 6.4 & 7.3 & 7.5 & 4.7 \\
\hline Stage I & 4.2 & 3.9 & 5.3 & 3.2 \\
\hline Stage II & 8.1 & 7.5 & 9.4 & 4.9 \\
\hline Stage III & 6.5 & 9.7 & 7.8 & 5.9 \\
\hline 90-day mortality (\%) & 11.3 & 11.2 & 10.9 & 7.2 \\
\hline Stage I & 8.3 & 7.1 & 8.0 & 5.6 \\
\hline Stage II & 13.0 & 11.0 & 12.6 & 8.0 \\
\hline Stage III & 11.9 & 14.5 & 11.8 & 8.0 \\
\hline 1-year mortality (\%) & 22.1 & 18.3 & 18.9 & 13.6 \\
\hline Stage I & 16.2 & 12.1 & 13.6 & 9.2 \\
\hline Stage II & 22.2 & 15.4 & 21.3 & 13.8 \\
\hline Stage III & 26.5 & 26.0 & 21.2 & 17.1 \\
\hline Excess 1-year mortality (\%) & 14.0 & 12.7 & 10.7 & 5.3 \\
\hline Stage I & 8.0 & 7.5 & 5.0 & 0.6 \\
\hline Stage II & 14.3 & 10.0 & 13.3 & 5.6 \\
\hline Stage III & 18.6 & 19.6 & 13.6 & 9.2 \\
\hline
\end{tabular}

overall mortality in elderly patients undergoing a colorectal resection in different North European countries. These high mortality rates are in line with a recent Dutch study where a one-year overall mortality up to $24 \%$ was found in stage I-III colorectal cancer patients aged 85 or older [9,16]. Another study including patients of 80 or older who underwent an elective colectomy from the Surveillance, Epidemiology and End Results (SEER) database showed a considerable lower 90-day overall mortality and a 1-year overall mortality of $7 \%$ and $14 \%$, respectively [17]. This difference might be explained by the fact that in our study both elective and emergency surgery were included of which the latter one is associated with higher postoperative mortality rates $[18,19]$.

The lowest short-term mortality rates for both colon and rectal cancer in the current study were seen in Sweden. There is no specific focus or dedicated program for elderly on national basis. A reason for these findings could be that Swedish surgeons might use a stricter selection of patients with increasing age as the percentage of patients who did not undergo a resection increased over time [20]. Therefore, in Sweden a frail patient may have been included to a lesser extent, with resultant higher survival rates. Another explanation could be improved multidisciplinary management along with the successfully implementation of specialized centralization of rectal cancer surgery in Sweden [20]. As a result, even on regional level there are high volume hospitals and high volume surgeons for rectal cancer patients. On the other hand, these results could be a reflection of the in general better overall survival of Swedish people. In the EUROCARE-5 study an agestandardized one-year survival of $82.5 \%$ was found in Sweden compared to $77.6 \%$ in Europe [5]. National welfare programs and the Swedish health care system which is known for their lead in transparency of quality indicators and quality improvement might have contributed to this [21].

From 1989 to 2011 colorectal cancer mortality decreased for both men and women in Belgium, Denmark, the Netherlands and Sweden as shown in a retrospective analysis of the WHO mortality database [22]. Our study showed that overall one year mortality in both colon and rectal cancer decreased during the study period in these four countries. In the Netherlands better survival was observed in both types of cancer, whereas in Belgium and Denmark this was most pronounced in colon cancer patients and in Sweden in rectal cancer patients. The decrease of short-term mortality over time can be explained by improvements in several fields. Firstly, perioperative care has been improved by enhancement of anesthesia techniques, such as restriction in intravenous fluid supply and preventing hypothermia $[23,24]$. Furthermore the successfully implementation of the Enhanced Recovery After Surgery (ERAS) 

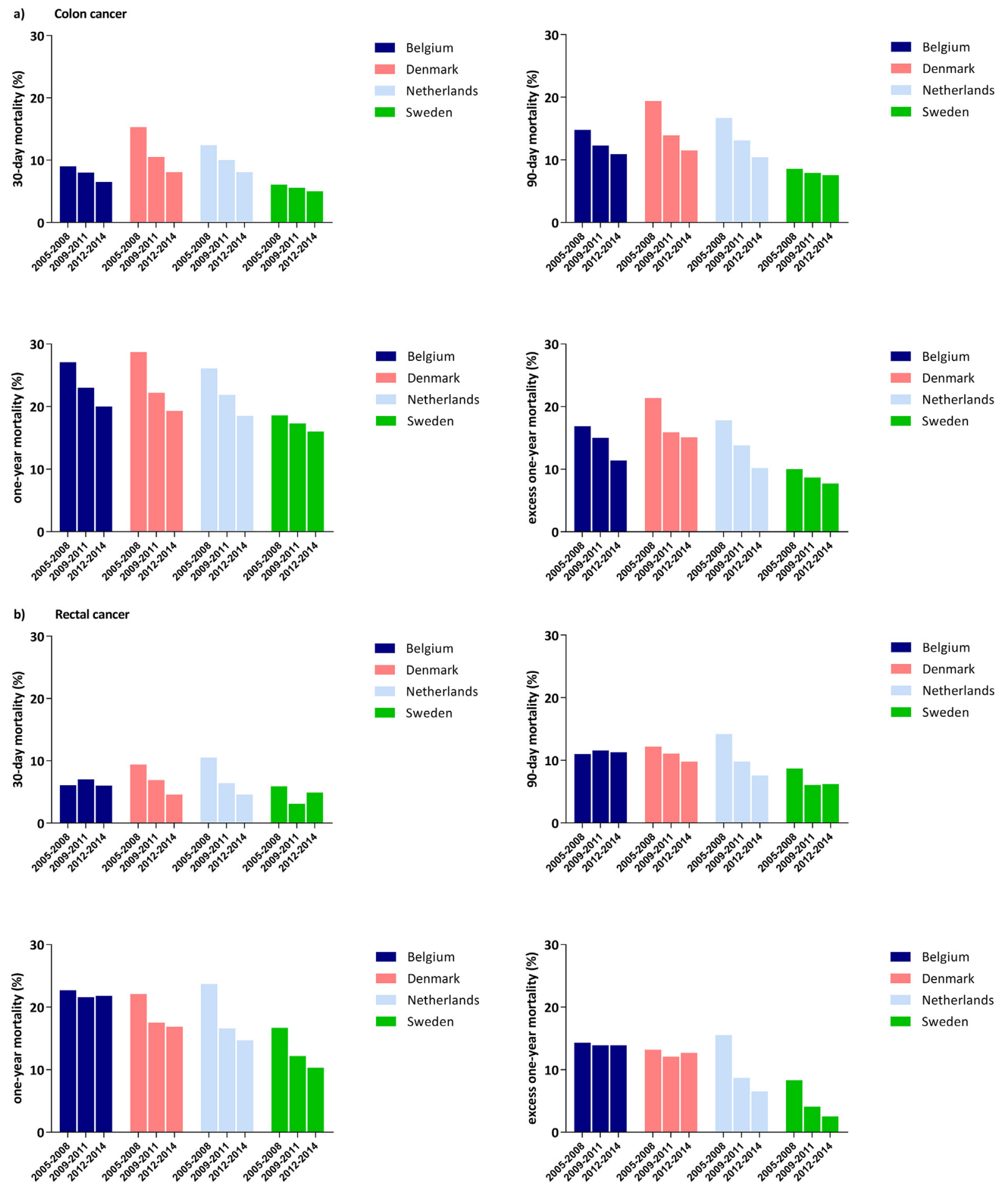

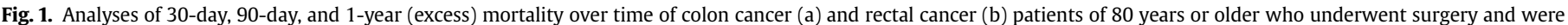
diagnosed during 2005 and 2014.

program could have played a role. The last decades there has been more focus on the perioperative care for patients and the ERAS program has become standard in colorectal cancer patients after it was developed in 2001 [25]. This evidence-based care has led to major improvements in clinical outcomes and costs [25]. A recent study investigated the benefits of the ERAS program in elderly colorectal cancer patients undergoing elective colorectal surgery compared to case-matched patients with conventional care [26]. Clear improvements were observed in the ERAS group compared to the conventional group. As a result the authors concluded that the same benefits due to ERAS program can be expected in elderly compared to their younger counterparts and that ERAS should be implemented in elderly CRC patients without reservations [26]. Other initiatives focused on perioperative care and fast mobilization after surgery could have also contributed to the improvement over time. Counseling regarding nutrition and exercising preoperatively might have been an important factor as well. Another explanation could be the increasing utilization of a minimally 
invasive approach [27]. Reduced mortality rates were seen with the minimally invasive approach compared to the open approach in a retrospective Dutch study and a Danish nationwide study, especially for the elderly $[27,28]$. Increasing use of bridge-to-surgery techniques with stent insertion or defunctioning stoma aiming to convert emergency cases to elective cases have also contributed to favorable change in short-term mortality [29]. Furthermore, the percentage of patients with colorectal cancer who underwent a resection decreased the last decade [30]. A better selection of vital patients (less frail patients) might also be partly responsible for the improvement over time. Finally, differences in the indication of (neo)-adjuvant chemo- and/or radiotherapy for older patients with colon- or rectal cancer could have played a role [31,32].

To our knowledge, this study contains the largest dataset regarding short-term mortality analyses of patients aged 80 or more undergoing a colorectal resection. Although we matched the excess mortality for age, sex, and stage, residual confounding between countries could have occurred. Confounders such as the number of comorbidities, frailty assessment, or emergency could have played a role in short term mortality differences between countries. The lack of data of frailty assessment can definitely be seen as a limitation of this study, Current cancer registries do not register this item but should consider to collect information such as frailty assessment, as that variable is highly important with interpreting results of elderly and mortality. Selection criteria for surgery within countries may be led by expected survival. This could result in selection bias in the comparison between countries. Which might have played a role in the current study, especially in this group of patients, as elderly are known for their heterogeneity.

Improved perioperative care and minimally invasive surgical approach seemed to have paid off with decreasing short-term mortality rates the last decade. Especially older frail patients are known to benefit from a minimally invasive approach due to reduced cardiopulmonary complications [33]. Further improvements in the perioperative care and increasing use of a minimally invasive approach might lead to a further decrease of short-term mortality rates.

Based on the findings of the current study we would like to address two points in order to improve the survival of elderly with colorectal cancer. First, our findings emphasize the importance of geriatric assessment. With this tool the presence of frailty can be identified, which is a strong predictor for both short- and long-term outcomes after gastrointestinal surgery [34]. Geriatric assessment can aid to indicate interventions aimed to optimize the condition of these elderly colorectal cancer patients before surgery with subsequently better postoperative outcomes. Second, short-term mortality rates are high in octogenarians with colorectal cancer and might indicate that a stricter selection of patients for surgery should be applied. This should be taken into consideration between clinician and patient in order to make a shared decision whether the risk accompanied with a major resectional surgery outweighs the benefit in terms of survival and of no risk of obstruction.

In conclusion, high short-term mortality rates were observed in octogenarians with colorectal cancer in a large population-based cohort. Short-term mortality differ across four North European countries. Short-term mortality rates decreased over time for both colon and rectal cancer patients in all countries.

\section{Conflict Of Interest}

All authors substantially contributed to the conception and design or analysis and interpretation of the data; drafting the article or revising it critically; and approved the final version. No conflicts of interest for all authors. This research did not receive any specific grant from funding agencies in the public, commercial, or non-profit sectors.

\section{Appendix A. Supplementary data}

Supplementary data to this article can be found online at https://doi.org/10.1016/j.ejso.2019.03.041.

\section{Funding}

The study was initiated by EUropean REgistration of Cancer CAre (EURECCA) which is funded by the European Society of Surgical Oncology (ESSO). ESSO did not have a role in the study design, data collection, analysis, interpretation of the data, writing of the manuscript, or the decision to publish.

\section{References}

[1] Ferlay J, Steliarova-Foucher E, Lortet-Tieulent J, et al. Cancer incidence and mortality patterns in Europe: estimates for 40 countries in 2012. Eur J Cancer 2013;49(6):1374-403.

[2] Ferlay J, Shin HR, Bray F, Forman D, Mathers C, Parkin DM. Estimates of worldwide burden of cancer in 2008: GLOBOCAN 2008. Int J Cancer 2010;127(12):2893-917.

[3] Surgery for colorectal cancer in elderly patients: a systematic review. Colorectal Cancer Collaborative Group. Lancet 2000;356(9234):968-74.

[4] Patel SS, Nelson R, Sanchez J, et al. Elderly patients with colon cancer have unique tumor characteristics and poor survival. Cancer 2013;119(4):739-47.

[5] Holleczek B, Rossi S, Domenic A, et al, On-going improvement and persistent differences in the survival for patients with colon and rectum cancer across Europe 1999-2007 - results from the EUROCARE-5 study. Eur J Cancer 2015;51(15):2158-68.

[6] Papamichael D, Audisio R, Horiot JC, et al. Treatment of the elderly colorectal cancer patient: SIOG expert recommendations. Ann Oncol 2009;20(1):5-16.

[7] Lemmens VE, Janssen-Heijnen ML, Houterman S, et al. Which comorbid conditions predict complications after surgery for colorectal cancer? World J Surg 2007;31(1):192-9.

[8] Janssen-Heijnen ML, Maas HA, Houterman S, Lemmens VE, Rutten HJ, Coebergh JW. Comorbidity in older surgical cancer patients: influence on patient care and outcome. Eur J Cancer 2007:43(15):2179-93.

[9] Dekker JW, van den Broek CB, Bastiaannet E, van de Geest LG, Tollenaar RA, Liefers GJ. Importance of the first postoperative year in the prognosis of elderly colorectal cancer patients. Ann Surg Oncol 2011:18(6):1533-9.

[10] Duraes LC, Stocchi L, Dietz D, et al. The disproportionate effect of perioperative complications on mortality within 1 Year after colorectal cancer resection in octogenarians. Ann Surg Oncol 2016;23(13):4293-301.

[11] accessed at 20-08-2018, https://shop.iknl.nl/shop/kankerzorg-in-beeld-deoudere-pati\%C3\%ABnt-(2016)/123187. 113.

[12] accessed at 02-10-2018, http://kvalitetsregister.se/englishpages/findaregistry/ registerarkivenglish/swedishcolorectalcancerregistryscrcr.2156.html.

[13] World Health Organisation. International statistical classification of disease and related health Problems. 2010. 10th revision.

[14] Greene FLPDL, Fleming ID, Fritz AG, et al. AJCC cancer staging manual. sixth ed. New York: Springer; 2002.

[15] Schiphorst AH, Verweij NM, Pronk A, et al. Age-related guideline adherence and outcome in low rectal cancer. Dis Colon Rectum 2014;57(8):967-75.

[16] Verweij NM, Schiphorst AH, Maas HA, et al. Colorectal cancer resections in the oldest old between 2011 and 2012 in The Netherlands. Ann Surg Oncol 2016;23(6):1875-82.

[17] Neuman HB, Weiss JM, Leverson G, et al. Predictors of short-term postoperative survival after elective colectomy in colon cancer patients $>\mid=80$ years of age. Ann Surg Oncol 2013;20(5):1427-35.

[18] Ming-Gao G, Jian-Zhong D, Yu W, You-Ben F, Xin-Yu H. Colorectal cancer treatment in octogenarians: elective or emergency surgery? World J Surg Oncol 2014;12:386.

[19] Iversen LH, Bulow S, Christensen IJ, Laurberg S, Harling H. Postoperative medical complications are the main cause of early death after emergency surgery for colonic cancer. Br J Surg 2008;95(8):1012-9.

[20] Kodeda K, Johansson R, Zar N, et al. Time trends, improvements and national auditing of rectal cancer management over an 18-year period. Colorectal Dis 2015;17(9):0168-79.

[21] accessed at 08-08-2018, http://docplayer.nl/331335-Rapport-zorg-voorwaarde-meer-kwaliteit-voor-minder-geld-wat-de-nederlandse-gezondheidszorg-kan-leren-van-zweden.html.

[22] Ait Ouakrim D, Pizot C, Boniol M, et al. Trends in colorectal cancer mortality in Europe: retrospective analysis of the WHO mortality database. BMJ 2015;351: h4970.

[23] Lassen K, Soop M, Nygren J, et al. Consensus review of optimal perioperative care in colorectal surgery: Enhanced Recovery after Surgery (ERAS) Group recommendations. Arch Surg 2009;144(10):961-9.

[24] Bainbridge D, Martin J, Arango M, et al. Perioperative and anaesthetic-related 
mortality in developed and developing countries: a systematic review and meta-analysis. Lancet 2012;380(9847):1075-81.

[25] Ljungqvist O, Scott M, Fearon KC. Enhanced Recovery after surgery: a review. JAMA Surg 2017;152(3):292-8.

[26] Tejedor P, Pastor C, Gonzalez-Ayora S, et al. Short-term outcomes and benefits of ERAS program in elderly patients undergoing colorectal surgery: a casematched study compared to conventional care. Int J Colorectal Dis 2018 Sep;33(9):1251-8.

[27] Hamaker ME, Schiphorst AH, Verweij NM, et al. Improved survival for older patients undergoing surgery for colorectal cancer between 2008 and 2011. Int J Colorectal Dis 2014;29(10):1231-6.

[28] Iversen LH, Ingeholm P, Gogenur I, Laurberg S. Major reduction in 30-day mortality after elective colorectal cancer surgery: a nationwide populationbased study in Denmark 2001-2011. Ann Surg Oncol 2014;21(7):2267-73.

[29] van Hooft JE, van Halsema EE, Vanbiervliet G, et al. Self-expandable metal stents for obstructing colonic and extracolonic cancer: european society of gastrointestinal endoscopy (ESGE) clinical guideline. Gastrointest Endosc
2014;80(5):747-61. e1-75.

[30] de Neree Tot Babberich MPM, Detering R, Dekker JWT, et al. Achievements in colorectal cancer care during 8 years of auditing in The Netherlands. Eur J Surg Oncol 2018;51(15):2158-68.

[31] Claassen YHM, Vermeer NCA, Iversen LH, et al. Treatment and survival of rectal cancer patients over the age of 80 years: a EURECCA international comparison. Br J Canc 2018;119(4):517-22.

[32] Vermeer NCA, Claassen YHM, Derks MGM, et al. Treatment and survival of patients with colon cancer aged 80 Years and older: a EURECCA international comparison. Oncol 2018;23(8):982-90.

[33] Gietelink L, Wouters MW, Bemelman WA, et al. Reduced 30-day mortality after laparoscopic colorectal cancer surgery: a population based study from the Dutch surgical colorectal audit (DSCA). Ann Surg 2016;264(1):135-40.

[34] Wagner D, DeMarco MM, Amini N, et al. Role of frailty and sarcopenia in predicting outcomes among patients undergoing gastrointestinal surgery. World J Gastrointest Surg 2016;8(1):27-40. 